\title{
SOCIOMETRIC RESEARCH IN THE SERVICE OF APPOINTING MANAGERS IN THE AGRICULTURAL PHARMACIES
}

\author{
Ivica Nikolićl, Jelena Vemić Djurković2, Ivana Marinović Matović3 \\ *Corresponding author E-mail: profilov@gmail.com
}

A R T I C L E I N F O
Original Article
Received: 30 September 2019
Accepted: 02 February 2020
doi:10.5937/ekoPolj2001009N
UDC 005.953.2:632

Keywords:

sociometric research, sociometric criteria, sociometric techniques and instruments, sociometric methods of classification, human resources management.

JEL: Q13, M12, M51
A B S T R A C T

The purpose of this paper is to prove possibility of the application of the sociometric method in human resources management with the aim of appointing managers in one organization. Based on the some results, published in the scientific papers, authors established general and particular hypothesis about applying sociometry as a research method in human resources management. The concrete research of the applications of sociometry for appointing managers was conducted in one company in Serbia. Sociometric research shows real relations in a social group, as well as the projection of the position of individuals, mutual attraction and rejection within the group. Presented research is one of the "pioneering" attempts of broader application of the sociometric method in human resources management with the aim of appointing managers in one organization, especially in Serbia.

(C) 2020 EA. All rights reserved.

\section{Introduction}

Sociometry is a method for describing, revealing and estimating the social status, structure and development by measuring the level of acceptance or rejection among individuals within groups (Maheshwari, 2011). It is a methodology which allows us to study choices, communication and models of interaction among individuals in a group which is performing a certain task. The basis of this methodology is the procedure that requires each member of a work team to choose, according to some determined,

1 Ivica Nikolić, Associate professor, Educons University, Faculty of Business Economics, 21208 Sremska Kamenica, Vojvode Putnika street no 87, Serbia, Phone: +381 63521 171, E-mail: profilov@gmail.com, https://orcid.org/0000-0001-7942-8779

2 Jelena Vemić Djurković, Associate professor, Educons University, Faculty of Business Economics, 21208 Sremska Kamenica, Vojvode Putnika street no 87, Serbia, Phone: +381 64160 8205, E-mail: jelena.vemic.djurkovic@educons.edu.rs, https://orcid.org/00000002-3379-6530

3 Ivana Marinović Matović, Assistant Professor, Addiko Bank AD, 11070 Novi Beograd, Bulevar Mihajla Pupina street no 6, Serbia, Phone: +381 60863 4004, E-mail: ivana.m.matovic@gmail.com, https://orcid.org/0000-0002-8273-4096, 
established criteria, one or more persons with whom they think they could cooperate successfully. Sociometry practically represents a study of connections - affinities among individuals in a work team. Sociometric research gives us results which enable us to intervene in a work team in order to increase creativity, leadership and innovation and thus increase the satisfaction of work team members and achieve better results. It shows patterns of the way in which individuals in a work team associate with each other, and when they act as a group in order to achieve a certain goal - finding a solution to a problem.

Sociometry has two main domains: research sociometry and applied sociometry (Hoffman, 2000; Maheshwari, 2011; Bansal, 2014). Research sociometry represents research activity conducted with groups with the goal of discovering socio-emotional connections in relations by using criteria defined in advance, for example which members of the group does one want as a work partner. Applied sociometry uses a series of methods which help people and groups to perceive, expand and develop their own existing psycho-social networks in relationships.

The concept of sociogram was introduced by (Moreno, 1978) and it represents, in the form of a diagram, corresponding relations among individuals within a group. The data from a sociogram can also be represented in a matrix called sociometric matrix. Sociogram is a very important tool in sociometric research. Its goal is to reveal group structures and the relationship each individual has with the group as a whole.

The broadest application of sociometry has been in pedagogy, sociology and psychotherapy. Cillessen, Jiang, West and Laszkowski, 2005, used this method in the study of friendships among children. Fredrickson and Furnham, 2004, used the sociometric technique in order to estimate the quality of life of children with difficulties in learning and in relations with their family members. Blatner, 2010 sees many advantages of this method, considers sociometry a relatively new field and thinks that what we have learned so far about the use of this method is probably just a part of what we still have to learn.

Some authors question the validity of this method because they think it does not measure anything useful. However, based on research conducted by a number of researchers, Mouton, Blake and Fruchter, 1995, concluded that the sociometric choice represents a useful method for measuring characteristics of individuals and groups. The authors (Campion, Medsker, Higgs ,1993) analyzed a significant number of applications of sociometry and concluded that the number of sociometric choices tends to predict criteria of efficiency such as productivity, the efficiency of the efforts made, the training ability and leadership.

The sociometric results can be applied when dealing with real problems in the practical domain (Hathaway, 2017). Sociometry as a methodology can provide all the necessary and important factors for appointing a work team or an individual - manager - by measuring the levels of acceptance or rejection among the individuals of a given group (Kurzman, 2008; Maheshwari, 2011). 
In the last few years, numerous scientific papers have dealt with the problem of appointing a work team made up of members capable of cooperating while dealing with joint problems (Ballesteros-Pérez, P. et al., 2012). In that sense, it has been stressed that organizational behavior and industrial and organizational psychology are very important factors for a team's functioning (Hollenbeck et al., 2004).

Unlike Team Formation Problem (TFP), a new term was defined (Gutiérrez et al., 2016) - a problem named Multiple Team Formation Problem (MTFP). It was developed based on TFP by expanding its dimensions and taking into account more projects and people's devotion to certain parts. Also, an optimization model was suggested for the posited problem.

Some authors have dealt with the problem of individual members of work teams, which is also very important for successful functioning of a work team as a whole (Campion et al., 1993).

In Ballesteros-Pérez, González-Cruz, Fernández-Diego, 2012, a new, original method, based on sociometry, is suggested for choosing members of a work team among the workers in the company in which the projects work tasks should be done.

\section{Materials and methods}

The subject of the research is the identification of strategic management's new approach in the process of selecting managers in the service industry organizations of smaller scale and of entrepreneurial type, and a presentation of a case study of applying sociometry as a research method with that objective.

The problem of the research is practical application of the sociometric method in human resources management of an organization with the goal of appointing managers, and including this research method in the arsenal of methods for choosing managers from an organization's internal resources.

The goal of the research was to identify the employee who represented 'the favorite person', that is, in the terminology of sociometry, 'a leader', in the sector of retail stores, who already had the integrity and respectability in the eyes of the workers and who positively influenced forming of relationships among the people within the group, and to appoint them manager.

General hypothesis $(\mathbf{H})$ is: "By applying sociometry as a research method in human resources management we obtain precise data about potential choices for managers from internal resources, and about appointing them to a certain managerial function within the organization.

Also, particular hypotheses arise from the research: H1 - "By using the sociometric method it is possible to identify the state of interpersonal relationships within the researched social group, to precisely determine its cohesion or expansion, as well as the affective atmosphere index and group tension index, and to present the results 
quantitatively." H2 - the sociometric method gives the top management a clear picture of the subjects' individual statuses within the researched group, based on which the top management can have the level of interpersonal relationships raised and group cohesion index improved.

During the research, analytical-synthetic method and the sociometric method were applied. An example of sociometric questionnaire as a technique for gathering data, and statistical method of data analysis in the form of calculating individual sociometric indices, quantitative presentation of results and graphic model of sociogram were presented.

The concrete research of the applications of sociometry for appointing managers was conducted in the one company in Serbia which has five (5) agricultural pharmacies.

\section{Candidate recruiting for management functions}

The company where the research was conducted has five (5) agricultural pharmacies. The total number of employees is 42 direct executors. Mentioned company has a simple organizational structure. Due to the increase of workload, a need for appointing a manager in the sector of retail stores (agricultural pharmacies) -5 in total, with the total of 10 workers - arose. The entrepreneur wanted to appoint a manager (recruitment) chosen from the internal resources within the organizational unit. At the request of the entrepreneur, is conducted sociometric research as the primary method for choosing the manager, surveying 10 female workers, and the results were then used for appointing the manager.

The filling of vacancies begins with the process which is usually called recruiting (providing, attracting) human resources. It is the process of identifying and attracting candidates whose abilities, professional and personal skills meet the requirements of the currently filled vacancies or future jobs (Pržulj, 2011; Arsenovic et al., 2017).

When recruiting candidates, organizations must also take into account the factors which can influence a candidate's job choice (White , 1961). For each individual, it is a very important life decision. In that situation, the individual is under the interactive influence of personal aspirations and characteristics (professional values, personal characteristics, needs, attitudes and similar) as well as under the influence of their impressions about the job and organization (real characteristics, the way in which the job has been presented, previous experience and the knowledge about the organization) (Pržulj, 2011). Candidate recruitment represents direct expression of the organization's employment policy and strategy, and this activity reflects the management's basic ideas and orientation regarding human resources. This is particularly visible in the answers to the following questions (Pržulj, 2011):

- What kind of people does the organization need?

- Which resources have the priority, internal or external?

- What is of primary importance when it comes to estimation? 
- Is the organization ready and how ready is it to invest in the future development of the employees, or is it looking for 'readymade' personnel; is the priority given to specialists or generalists?

- Which criteria will be used in the selection?

The advantages of choosing job candidates from internal resources over choosing them from external ones are:

- Knowing the candidates; motivational effect of the given chance for promotion;

- Candidates know the organization and its way of work well;

- Better use of the employees' potentials due to using their abilities on other jobs as well;

- Higher reliability of estimation;

- Speed and lower costs;

- Feeling of belonging, and feeling that the company takes care of good workers.

Special attention is required when choosing and appointing a manager within a functional social i.e. organizational group, considering the newness of the position, power and authority, power to make decisions and assume responsibility for achieving the organization's planned goals. The bearer of this 'new role', who was until yesterday at the same organizational level as others, assumes leadership under the hypothesis of having highly ranked personal skills and authority over workers, which should guarantee good relations among the people and the platform for achieving the organization's goals.

However, it is hard to claim with certainty that choice will be 'the right one' if the relations among the members of the group, the existence of cliques, desirable and undesirable individuals, a potential 'leader' etc. are not identified. Conducting sociometric research in a social group provides, with precisely these results, thus also giving clear directions for identifying 'the right manager' within a group (organization), as well as showing the range of the existing interpersonal relations, attitudes and aspirations of individuals (with their first and last name) within a group, which represents a 'scanner' of an organizational unit, and is the base for further study and redistribution of employees' tasks and jobs, with a high degree of guarantee of company's efficiency and effectiveness.

Sociometry is usually applied to social groups consisting of up to 40 members (subjects), where it can be successfully identified the socio-emotional relations within a group, as well as harmony or potential disharmony of interpersonal relations within a social group.

Great importance for this paper have the results obtained by sociometric research in terms of identifying a 'leader', individual suitable for a managerial position, person seen as a role model and similar (Rostampoor - Vajari, 2012). Results differentiated in this way give the 'top' management a clear picture enabling them to choose 
candidates for positions in higher and middle management levels from the existing internal resources, with a high degree of approval among the subordinates of the newly appointed manager, which is an important precondition for successful functioning of an organization and achieving the set goals. Equally important are the findings about the sustainability and state of interpersonal relations within the social group (organization) that is being studied, which are also clearly presented by sociometric research and are an important constituent of employees' organizational behavior.

The primary postulates of each sociometric research are considerations of methodological requirements in terms of defining (Maheshwari, 2011):

- sociometric criteria;

- choice of sociometric technique and instruments;

- distribution (display) of results obtained by sociometric research.

\section{Selection of sociometric criteria}

Depending on the goals and purpose of the sociometric research that is being conducted, one of the two kinds of criteria (social or intellectual) will be dominant. Considering the fact that the purpose of this paper is to present sociometric research whose goal is identifying the status of candidates for managerial positions in a functional organization or company with a smaller number of employees (up to 40 workers), most of the criteria will be from the domain of social criteria (about $70 \%$ ), and the rest from the domain of intellectual criteria (team work on certain tasks).

According to Jacob Moreno (Moreno, 1966), in order for sociometry to be fair it must satisfy the following conditions:

- data confidentiality - the data will not be publically disclosed because it is important for the subjects' motivation,

- subjects' motivation - the data can be used for the reorganization of the group in accordance with its members' wishes,

- limited size of the group - if the group is too big, the relationships within it are not close enough and subjects exclude some members from their choice only because they do not know them well enough. Sociometric research only makes sense in a group that has a size of a class (about 30 and not more than 40 individuals),

- selection criteria must be utterly explicit. Questions must be clear and concrete, not ambiguous and multidimensional.

When selecting sociometric criteria, it is necessary to make sure they are logical and that they apply to the activities which are important for the individual and for the group (organization) itself. In order for the results to be valid it is also necessary to meet the necessary preconditions when selecting sociometric criteria, first and foremost the following ones:

- the members of the group must share working space in real time (presence of 
permanent communication and perception within the organization);

- the researcher or interviewer must be trusted by the entire group, and discretion must be guaranteed;

- the members of the group must know each other (at least for several months);

- when defining the criteria it is obligatory to precisely say how many individuals will be chosen and which population will be subjected to the research.

Considering the methodological requirements, it is clear that the sociometric criteria play the essential role in each sociometric research. They are a unique core, and choosing or rejecting group members depend on them (Ilic, 2013).

Sociometric research for the needs of the 'top' management of an organization will first serve to obtain the relevant results regarding appointment of managers in a functional work unit, as well as regarding the level of interpersonal relations in it. Sociometric criteria will be defined according to the context of that goal and presented through the following directions and questions (Petrović, 2015):

- questions concerning team work in some group activity (walk in nature, gardening tasks),

- questions for identifying the leader ("Under whose leadership would you like to perform your activities at work?". An example for the selection of manager in a financial sector: "Who would you like to do the company's annual financial statement with?". An example for shop assistants in a shop: "Who would you like to work with in your shift?"),

- group members can make positive and negative choices for certain activities,

- the number of choices can be limited to the number of members (example: two positive ones and one negative).

\section{Selection of sociometric techniques and instruments}

Banđur \& Potkonjak, 1999 say that sociometric method includes the use of testing and surveying techniques and the use of the following instruments: sociometric test, sociometric questionnaire and role-playing.

Moreno (Moreno, 1978) says that while conducting sociometric research the following methodological requirements should be taken into account:

- the group must be well defined and choosing and rejecting limited to the group members only;

- the subjects should be provided with unlimited number of choices and rejections;

- the criteria activities should be clearly defined so that they are understandable to all group members;

- the results obtained by sociometric questionnaire should be used for the group's restructuring; 
- the subjects should be allowed to anonymously choose and reject, the other group members should not be informed about the answers (Ilic, 2013).

Sociometric questionnaire should contain questions that all the group members will be asked, each member should be asked to give opinion about everyone, to make their personal choice (giving first and last name), to say with whom they would like to participate in a real or imagined activity, but also to say with whom they would not like to. Also, two modified questions can be added to these questions, asking the individual to say who they think chose them in a positive sense and who chose them in a negative sense regarding the participation in the activities mentioned in the first two questions. These questions enable us to see if the subject knows their social status within the group.

The data regarding interpersonal relations within a group allows the "top" management to take adequate steps and measures for improving or consolidating interpersonal relations within the surveyed organization, which is also a benefit obtained by sociometric technique.

\section{Distribution of the results obtained by sociometric research}

In sociometry, there are two ways of distributing the obtained results (Moreno, 1996; Maheshwari, 2011):

- graphic (sociogram)

- quantitative (sociometric matrix)

Graphic display of the results obtained (Zakharchyn \& Kosmyna, 2015) is a visual representation of all subjects on a sociogram, with marked affinity directions (positive and negative) among the members of the group (organization) surveyed. Each member of the surveyed group is displayed with a specific mark (first and last name initials, numbers etc.). The direction of the choice made is represented by an arrow, a solid line with an arrow representing a positive choice, and a broken line with an arrow a negative choice, or rejection, of that group member. Graphic representation is only applicable in smaller organizations or organizational units with a smaller number of employees, because the results on a sociogram must be clear and easy to perceive.

Quantitative display of results is actually a mathematical model of sociometric matrix making, where the use of defined formulae gives us three types of results:

- individual sociometric index (the status of each subject within an organization);

- group sociometric index (it shows interpersonal relations and the status of a group within a bigger unit);

- the state of social relations and the level of their disharmony within an organization.

When making a sociometric matrix, positive answers are marked by $(+)$, plus sign inside brackets, and negative ones by (-), minus sign inside brackets, after the mark designating a subject. 
The status of each individual within the group surveyed represents the Individual Sociometric Index, and it can be:

- positive selection status IS (+), and it is calculated using the formula: $\operatorname{Do}(+) \mathrm{N}-1$

- negative selection status IS (-), and it is calculated using the formula: Do(-) N-1

- positive expansion IE $(+)$, and it is calculated using the formula: $\mathrm{Da}(+) \mathrm{N}-1$

- negative expansion IE (-), and it is calculated using the formula: $\mathrm{Da}(-) \mathrm{N}-1$

The meaning of the symbols in the formula:

$\mathrm{N}=$ the number of subjects within a group, $\operatorname{Do}(+)=$ the total number of the positive choices that the subject received, Do(-) = the total number of the negative choices that the subject received, $\mathrm{Da}(+)=$ the total number of the positive choices that the subject made, $\mathrm{Da}(-)=$ the total number of the negative choices that the subject made.

The indicators of the structure of relations within a group or a group's position within a bigger unit represent the Group Sociometric Index, which can be expressed in the following way:

Group Expansion Index (GEI) $=\operatorname{sum}(+) /$ N, where sum $(+)=$ the sum of all positive votes, and $\mathrm{N}=$ the number of subjects, and Group Cohesion Index $(\mathrm{GCI})=\mathrm{R} / \mathrm{Rm}$,

where $\mathrm{R}=$ the number of mutual choices within a group; $\mathrm{N}=$ the number of subjects; $\mathrm{Rm}=$ the number of possible mutual choices $(\mathrm{Rm}=\mathrm{N}(\mathrm{N}-1) / \mathrm{N}$ (Petrović 2015).

The state of a group's (organization's) social relations and the level of their disharmony can be expressed in the following way:

Group Tension Index (GTI) = sum (-) / N,

where sum $=$ the sum of all negative votes, and $\mathrm{N}=$ the number of subjects, or:

Affective Atmosphere Index (AAI) = sum (+) (sum (+) + sum (-));

Where sum $(+)=$ the sum of all positive votes, and sum $(-)=$ the sum of all negative votes.

Higher value of GEI indicates better interpersonal relations within a group. Higher value of GTI indicates higher intolerance and unfavorable socio-emotional climate within a group. The value of AAI, if all the votes are negative, is zero.

Making a sociometric matrix is a far more complex process of analysis of the data obtained by sociometric research (Moreno, 1996), but it is necessary for a precise insight into the results which the 'top' management needs when making a decision regarding appointment of a manager. The best solution, if a surveyed group is not big, is to accompany a sociometric matrix with a graphic display in the form of a sociogram, which completes the picture regarding results. 


\section{Research results}

The sociometric research surveyed 10 female workers in 5 retail stores - agricultural pharmacies. The instrument used for gathering data was a sociometric questionnaire containing two questions, i.e. sociometric criteria, adjusted to the goal of the research, those questions being:

- With whom would you like to work in the store? (write their first and last name) Give a reason.

- With whom would you not like to work in the store? (write their first and last name) Give a reason.

It was possible to give maximum two positive and two negative answers.

The sociometric questionnaire was filled in individually, and the subjects were explicitly told that the results would not be disclosed to anyone but to the person who had requested the research.

In the sociogram, the subjects are marked by the initials of their first and last names, and they are marked by circles containing their initials (Figure 1.). The solid lines with arrows represent positive answers (desirable), and the broken lines with arrows represent negative choices. It is necessary to be very careful when it comes to making a sociogram and to how and with whom to use it (Jones, 2006). A sociogram should be simple and easy to use. Then it can be used successfully for estimation of different relations within a group - work team (Leung et al., 2006; Rostampoor - Vajari, 2012).

Figure 1. Sociogram

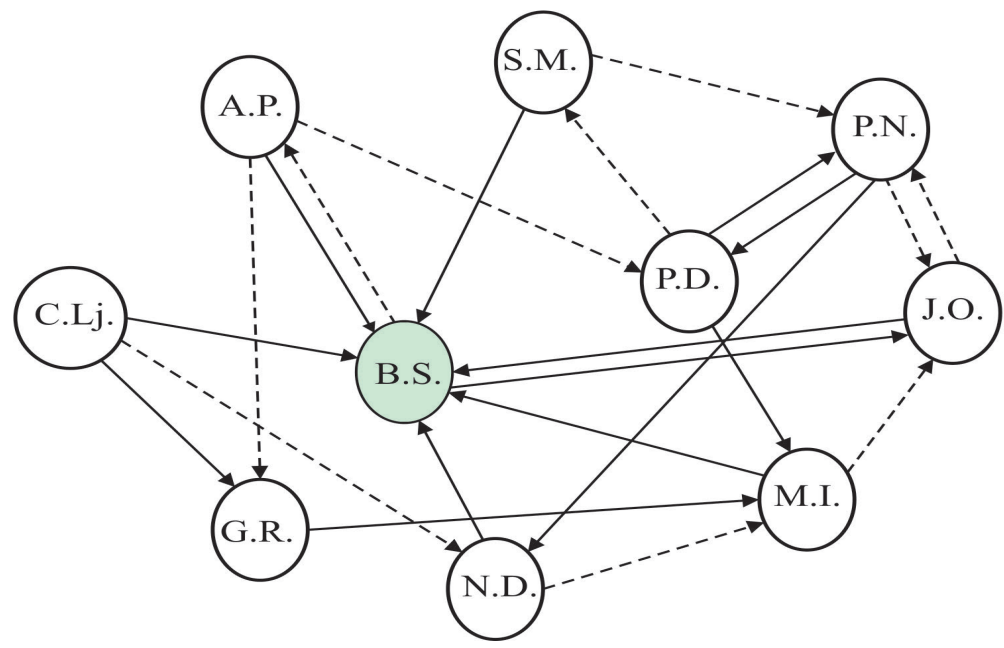

Source: Own authors research

After the graphic display in a sociogram, the obtained results were represented in a sociometric matrix (Table 1.). 
Table 1. Sociometric matrix

\begin{tabular}{|c|c|c|c|c|c|c|c|c|c|c|}
\hline \multicolumn{9}{|c|}{ CHOSEN } \\
\hline Initials of respondents & A.P. & S.M. & P.N. & J.O. & M.I & N.D. & G.R. & C.Lj. & B.S. & P.D. \\
\hline A.P. & & & & & & & - & & + & - \\
\hline S.M. & & & - & & & & & & + & \\
\hline P.N. & & & & - & & & & & & + \\
\hline J.O. & & & - & & & & & & + & \\
\hline M.I. & & & & - & & & & & + & \\
\hline N.D. & & & & & - & & & & + & \\
\hline G.R. & & & & & + & & & & & \\
\hline C.Lj. & & & & & & - & + & & + & \\
\hline B.S. & - & & & + & & & & & & \\
\hline P.D. & & - & + & & + & & & & & \\
\hline CHOOSES & & & & & & \\
\hline
\end{tabular}

\section{Source: Own authors research}

Based on the data obtained from the sociometric matrix, the subjects can be grouped in sociometric status groups (Table 2.).

Table 2. Classification of respondent in groups of sociometric status

\begin{tabular}{|c|c|c|c|c|}
\hline $\begin{array}{c}\text { Groups of sociometric } \\
\text { status }\end{array}$ & $\begin{array}{c}\text { Score of positive } \\
\text { choice }\end{array}$ & $\begin{array}{c}\text { Score of negative } \\
\text { choice }\end{array}$ & $\begin{array}{c}\text { Score of social } \\
\text { preference }\end{array}$ & $\begin{array}{c}\text { Score of social } \\
\text { influence }\end{array}$ \\
\hline Popular & $>0$ & $<0$ & $>1$ & \\
\hline Rejected & $<0$ & $>0$ & $<-1$ & \\
\hline Controversial & $>0$ & $<0$ & & $<1$ \\
\hline Neglected & $<0$ & $<0$ & & $<-1$ \\
\hline Average & \multicolumn{4}{|c|}{} \\
\hline \multicolumn{5}{|c|}{ not belong to the specified scores } \\
\hline
\end{tabular}

Source: authors adapted by (Ilic, 2013)

The quantitative representation of results gives us the values of the Individual Sociometric Index (Is) - positive Is (+) and negative Is (-) - and the values of the Group Sociometric Index, i.e. the Group Expansion Index (GEI), the Group Cohesion Index (GCI) as well as the indexes indicating the state of interpersonal relations and the level of their disharmony within a group: the Group Tension Index(GTI) and the Affective Atmosphere Index (AAI). The results obtained are represented in Table 3. 
Table 3. Results of sociometric indexes

\begin{tabular}{|c|c|c|c|c|}
\hline $\begin{array}{c}\text { Initials of } \\
\text { respondents }\end{array}$ & $\begin{array}{c}\text { Positive elective } \\
\text { status } \\
\text { Is(+) }\end{array}$ & $\begin{array}{c}\text { Negative elective } \\
\text { status } \\
\text { Is(-) }\end{array}$ & $\begin{array}{c}\text { Positive } \\
\text { expansiveness } \\
\text { Ie(+) }\end{array}$ & $\begin{array}{c}\text { Negative } \\
\text { expansiveness } \\
\text { Ie(-) }\end{array}$ \\
\hline A.P. & 0,11 & 0,11 & 0 & 0,11 \\
\hline S.M. & 0 & 0,11 & 0,11 & 0,11 \\
\hline P.N. & 0,11 & 0,22 & 0,22 & 0,11 \\
\hline J.O. & 0,11 & 0,22 & 0,11 & 0,11 \\
\hline M.I. & 0,22 & 0,11 & 0,11 & 0,11 \\
\hline N.D. & 0,11 & 0,11 & 0,11 & 0,11 \\
\hline G.R. & 0 & 0 & 0,11 & 0,11 \\
\hline C.Lj. & 0 & 0 & 0,22 & 0,11 \\
\hline B.S. & 0,67 & 0 & 0,11 & 0,11 \\
\hline P.D. & 0,11 & 0,11 & 0,11 & 0,11 \\
\hline
\end{tabular}

Source: Own authors research

Based on the results obtained it can be concluded that the values of the sociometric indexes are:

$\mathrm{GEI}=1.10, \mathrm{GCI}=0.22, \mathrm{GTI}=1, \mathrm{AAI}=0.55, \mathrm{R}=2 ; \mathrm{Rm}=9 ; \mathrm{N}=10 ; \operatorname{sum}(+)=12 ; \operatorname{sum}(-)=10$

\section{Discussion}

Considering the goal of the research, it can be concluded that the subject B.S. is the best person to be appointed manager in the company. Based on the research, the subject gets the title of a 'leader' or a popular person. Reasons: the value of the Leadership Index (Lx) for B.S. is 7, which is a far higher index value than the index value of the person immediately after them (3), and the rejection index (Ex) is 1, which does not surpass the average Ex of other subjects within the group.

We also identified undesirable (rejected) subjects, who got two negative points, P.N. and J.V., but considering the small index value it can be concluded that it is not a prominent characteristic of the individuals within the group nor of the group itself.

Based on the mutual choices, we revealed 'cliques': J.O. and B.S.; and P.N. and P.D. Considering the fact that according to the results B.S. should be appointed manager, it is to be expected that, if she can personally name them, her assistant or her substitute will be J.O.

There are no 'abstainers' within the group. The results show that there are no persons whom the others chose and who did not choose others.

Mutual rejection or mutual hostility was identified between P.N and J.O. because they gave each other negative votes.

Unreciprocated choice was revealed between B.S and A.P. A.P. chose B.S. but B.S. rejected her. The conclusion is that B.S. has had some negative experience with and has some negative opinions concerning A.P., and A.P is not aware of that. 


\section{Conclusion}

Some of the forms of expressed classifications according to the sociometric results can be presented in the following way:

- The popular ones (leaders) - members who have at least 13 or more positive votes. This information is the most important for the "top" management and for this paper.

- The rejected ones - they choose others, but for others are a negative choice;

- The unpopular ones - members who have 13 negative votes;

- The abstainers - they do not choose others, but others choose them;

- The lonely ones - nobody chooses them and they do not choose anyone;

- Mutual attraction or mutual rejection - when two members choose each other as a positive choice (attraction) or as a negative choice (rejection).

- Unreciprocated choice - when one of the subjects chooses another as a positive choice but the other one chooses them as a negative choice.

Based on the conducted research, personal experience and data from literature (Rostampoor - Vajari, 2012) it can be concluded when it is necessary to use sociometry:

- When it is necessary to study group relations which could disable people from achieving good work results,

- When it is necessary to move one's own organization from isolated work units to collaborative groups,

- When we want to strengthen work teams working in specific situations,

- When it is necessary to identify and solve the problems of group conflict, trust and identity,

- When we want to develop behavior suitable for our ideal work culture,

- When it is necessary to integrate consideration, feeling and action in business relations,

- When it is necessary to free informal leadership abilities within one's own organization.

The results presented in this paper and their description represent the starting base and directions for a possibility of a broader application of sociometric research in the service of appointing managers in each organizational unit by the "top" management whose philosophy is to choose personnel from internal (their own) resources. In this way the established hypothesis is confirmed.

The conducted research and the obtained data confirm the general hypothesis $(\mathrm{H})$ and it can be concluded that "by applying sociometry as a research method in human resource management we get precise data about the potential choice for managers from internal resources". The implementation of sociometry as a scientific method which modern 
strategic management should use to see the level of interpersonal relationships in their organizations and organizational units in order to improve them (which is the basic precondition for achieving goals and increasing the organization's efficiency) represents the confirmation of both particular hypotheses $(\mathrm{H} 1$ and $\mathrm{H} 2)$. Quantitative representation of the results concerning individual and group indices gives us a clear picture about each individual and about the group as a whole and all relationships that function within it.

It should be also mentioned that the research presented in this paper is one of the 'pioneering' attempts at a broader application of the sociometric method in human resources management with the aim of appointing managers in an organization, considering the fact that this technique is very often used in pedagogical research. In Serbia, as well as in the wider region, this is the first research of this kind.

\section{Conflict of interests}

The authors declare no conflict of interest.

\section{References}

1. Arsenović-Pavlović, M., Jolić, Z., \& Antić, S. (2017): Pedagogical Psychology (in Serbian). Faculty of Special Education and Rehabilitation, Belgrade. ISBN 97886-6203-091-7.

2. Ballesteros-Pérez, P., González-Cruz, M., \& Fernández-Diego, M. (2012): Human resource allocation management in multiple projects using sociometric techniques. International Journal of Project Management,30, 901-913. doi: 10.1016/j. ijproman.2012.02.005

3. Bandjur, V., \& Potkonjak, N. (1996): Pedagogical researches at school (in Serbian). Faculty of Teacher Education, Belgrade.

4. Bandjur, V., \& Potkonjak, N. (1999): Methodology of Pedagogy (in Serbian). Association of Pedagogical Societies of Yugoslavia, Belgrade. 59-86.

5. Bansal, S. (2014): Sociometry - a conceptual introduction. International Journal of Education and Science Research Review,1, 5, 147 - 153.

6. Blatner,A. (2010): Sociometry: the dynamics of rapport. Retrieved from https:www. blatner.comadampdntbksociom-dynrapport, accessed, December 16th 2017.

7. Campion, M.A., Medsker, G.J., \& Higgs, A.C. (1993): Relations between work group characteristics and effectiveness: implications for designing effective work groups. Personnel Psychology 46, 823-847. doi: 10.1111/j.1744-6570.1993.tb01571.x

8. Cillessen, A. H. N., Jiang, X. L.West, T. V., \& Dagmara Klaszkowski, D. K. (2005): Predictors of dyadic friendship quality in adolescence. International Journal of Behavioral Development, 29, 2, 165-172. doi: 10.1080/01650250444000360

9. Frederickson, N.L., \& Furnham, A.F. (2004): Peer-assessed behavioural characteristics and sociometric rejection: Differences between pupils who have moderate learning difficulties and their mainstream peers. British Journal of Educational Psychology, 74, 391-410. doi: 10.1348/0007099041552305 
10. Gutiérrez, J. H., Astudillo, C., A., Ballesteros-Pérez, P., Mora-Melià, D., \& Candia-Véjar, A. (2016): The multiple team formation problem using sociometry. Computers \&OperationsResearch, 75, 150-162. doi: 10.1016/j.cor.2016.05.012

11. Hathaway J. (2017):Sociometric Mapping for Predictive Performance Analysis: The Measurement of Attitudes of Social Acceptance or Rejection through Expressed Preferences among Members of a Social Grouping. Universal Journal of Psychology, 5, 6, 253-261, doi: 10.13189/ujp.2017.050603

12. Hoffman, C. (2000). Introduction to Sociometry. Retrieved from http:www. hoopandtree.orgcons_sociometry_introduction.pdf; accessd, January 15th 2018.

13. Hollenbeck, J.H., Scott, D., \& Guzzo, R. (2004): Bridging the Gap between IO research and HR practice: improving team composition, team training and task design. Human Resource Management, 43, 353-366. doi: 10.1002/hrm.20029

14. Ilić, M. (2013): Sociometric researches in pedagogy (in Serbian): Zbornik Instituta za pedagoška istraživanja, 45, 1,24-41.

15. Jones, D. (2006):Sociometry and Social Network Analysis: Applications and Implications, ANZPA Journal, 15, 77-85

16. Kurzman, C. (2008): Sociometry. In International encyclopedia of the social sciences, 2nd edition. Macmillan Reference USA, 390-392.

17. Leung, B. P., \& Silberling, J. (2006): Using Sociograms to Identify Social Status in the Classroom. The California School Psychologist, 11, 57-61.

18. Maheshwari V., K. (2011): Introduction to Sociometry. Retrieved from http:www. vkmaheshwari.comWP?p=50; accessed, December 12th 2017.

19. Moreno J. L. (1978): Who Shall Survive. Foundations of Sociometry, Group Psychotherapy and Sociodrama. Beacon House Inc.

20. Moreno J. L. (1996): Basics of sociometry (in Serbian). Methodology of empirical scientific research, University of Belgrade, 673-692.

21. Mouton J. S., Blake R. R., \& Fruchter B. (1955): The Validity of Sociometric Responses. Sociometry, 18, 3, 181-206.

22. Petrović V. (2015): Sociometric Questionnaire-Practice on Professional Practice. Retrieved from https:www.tapatalk.com/groups/razvojnaipedagoskapsihologija/ sociometrijski-upitnik-ve-ba-na-profesionalnoj-pra-t4.html; accessd, December 18 th 2017.

23. Pržulj, Ž. (2011): Human Resources Management, Educons University, Novi Sad.

24. Rostampoor -Vajari, M. (2012): What Is Sociometry and How We Can Apply It in Our Life? Advances in Asian Social Science (AASS), 2, 4,570-573.

25. White H. (1961): Management Conflict and Sociometric Structure. American Journal of Sociology, 67, 2, 185-199. doi:10.1086/223084

26. Zakharchyn H. M., \& Kosmyna Y. M. (2015): Application of modern methods of sociometric analysis for modelling personnel optimal behavior at the enterprise. Academic Journals \& Conferences of Lviv Polytechnic National University, 2, 1, 33-38. 